\title{
CAN WE PRESERVE PHYSICALLY MEANINGFUL "MACRO" ANALYTICITY WITHOUT REQUIRING PHYSICALLY MEANINGLESS “MICRO” ANALYTICITY?
}

\author{
Olga Kosheleva \\ Ph.D. (Phys.-Math.), Associate Professor, e-mail: olgak@utep.edu \\ Vladik Kreinovich \\ Ph.D. (Phys.-Math.), Professor, e-mail: vladik@utep.edu \\ University of Texas at El Paso, El Paso, Texas 79968, USA
}

\begin{abstract}
Physicists working on quantum field theory actively used "macro" analyticity - e.g., that an integral of an analytical function over a large closed loop is 0 - but they agree that "micro" analyticity - the possibility to expand into Taylor series - is not physically meaningful on the micro level. Many physicists prefer physical theories with physically meaningful mathematical foundations. So, a natural question is: can we preserve physically meaningful "macro" analyticity without requiring physically meaningless "micro" analyticity? In the 1970s, an attempt to do it was made by using constructive mathematics, in which only objects generated by algorithms are allowed. This did not work out, but, as we show in this paper, the desired separation between "macro" and "micro" analyticity can be achieved if we limit ourselves to feasible algorithms.
\end{abstract}

Keywords: mathematical foundations of physics, analytical function, constructive mathematics, feasible algorithms.

\section{1. "Macro" vs. "Micro" Analyticity: Formulation of the Problem}

Smoothness in physics. On macro-level, we observe many non-smooth and even discontinuous phenomena:

- earthquakes,

- phase transitions, etc.

However, on the micro-level, all equations and all phenomena are smooth - and even analytical; see, e.g., $[4,10]$. Some of these phenomena are very fast - so we perceive them as discontinuous.

Analyticity. For complex numbers, smoothness implies analyticity.

Analyticity has been successfully used in quantum field theory. For example, to compute the values of some integral expressions, it is convenient to use the fact 
that for an analytical function, a contour integral over a closed loop is 0 :

$$
\int_{\gamma} f(z) d z=0
$$

or it is equal to an explicit expression in terms of the poles.

How this "macro" analyticity can help physics. By using a loop $[-N, N] \cup \gamma^{\prime}$, we can replace a difficult-to-compute integral over real numbers $\int_{-N}^{N} f(x) d x$ with an often-easier-to-compute integral over the complex values $\int_{\gamma^{\prime}} f(z) d z$. This idea - mostly pioneered by Nikolai Bogolyubov (see, e.g., [3]) - led to many successful applications.

This "macro" analyticity has been confirmed by many experiments and makes perfect physical sense.

But what about "micro" analyticity? The problem is that in traditional mathematics, such "macro" analyticity is equivalent to "micro" one, that the corresponding dependencies can be expanded in Taylor series:

$$
f(z)=a_{0}+a_{1} \cdot\left(z-z_{0}\right)+a_{2} \cdot\left(z-z_{0}\right)^{2}+\ldots+a_{n} \cdot\left(z-z_{0}\right)^{n}+\ldots
$$

In the opinion of physicists, however, this "micro" analyticity does not make direct physical sense, since on the micro level, quantum uncertainty makes exact measurements impossible.

Can we preserve physically meaningful "macro" analyticity without requiring physically meaningless "micro" analyticity?

\section{Khalfin's Idea: First Attempt}

Maybe constructive mathematics can help? The equivalence between "macro" and "micro" analyticity holds in traditional mathematics, where, crudely speaking, we only care about the existence of different objects - but not about algorithms for computing these objects.

The algorithmic problems are important. So, to deal with these problems, researchers have come up with the idea of constructive mathematics, where we say that an object exists only if we have an algorithm for constructing this object; see, e.g., $[1,2,11]$.

In constructive mathematics, some equivalence results of traditional mathematics hold - in the sense that equivalence is algorithmic - while other equivalence results do not hold. So, in early 1970s, Leonid Khalfin, a specialist in mathematical physics from St. Petersburg, Russia, suggested that maybe the use of constructive mathematics can help us preserve physically meaningful "macro" analyticity without requiring physically meaningless "micro" analyticity?

This did not help. By the early 1970s, specialist in constructive mathematics have thoroughly studied complex analysis; see, e.g., $[1,6,8]$. Actually, the 1972 talk of Vladimir Overkov (one of the constructive mathematics pioneers), the talk whose results later appeared in [8] - this talk inspired Khalfin's suggestion. 
Unfortunately, these constructive mathematics results showed that in constructive mathematics, "macro" analyticity still implies the "micro" one; this was pointed out almost right away by Vladimir Lifschitz - another pioneer of constructive complex analysis, the authors of a paper [6]. He pointed out that each coefficient $a_{n}$ of the Taylor series can be determined by the following formula:

$$
a_{n}=\frac{1}{2 \pi \cdot \mathrm{i}} \cdot \int_{\gamma} \frac{f(z)}{\left(z-z_{0}\right)^{n+1}} d z,
$$

and in constructive mathematics, an integral of a computably continuous function is computable $[1,2,11]$.

\section{Problem Revisited}

Main idea. The above derivation of "micro" analyticity from the "macro" one is based on the usual constructive mathematics. In this approach, existence of an object means, in effect, the existence of an algorithm producing more and more accurate approximations to this object - irrespective to how long this algorithm may take.

A more realistic idea is to only allow feasible (= polynomial-time) algorithms; see, e.g., [5,9]. It turns out that in this case, Khalfin's dream can be materialized. Namely:

- while there exists an algorithm computing, for each computable macro analytical function, all the terms in its Taylor series expansion,

- it turns out that the computation time of this algorithm seems to grow exponentially with the number $n$ of the term - so such computations are probably not feasible.

Let us provide arguments in favor of this conclusion.

Explanation. We have a computable function $f(z)$. This means that we can, given $z$, compute $f(z)$.

For simplicity, we can also assume that we know the upper bound $D$ on $\left|f^{\prime}(z)\right|$ : $\left|f^{\prime}(z)\right| \leqslant D$.

Computation of the $n$-th Taylor coefficient $a_{n}$ is based on the formula (1). Here, the simplest possible loop $\gamma$ around the point $z_{0}$ is a circle of some small radius $r<1$. For this loop, $\left|z-z_{0}\right|=r$.

We want to compute $a_{n}$ with a given accuracy $\varepsilon>0$. This means that we need to compute the corresponding integral with accuracy $\varepsilon^{\prime}=2 \pi \cdot \varepsilon$.

By definition, an integral is a limit of integral sums. So, in general, a natural way to compute an integral $\int g(z) d z$ is to consider the corresponding integral sum

$$
\sum g\left(z_{i}\right) \cdot \Delta z \text {, with }\left|z_{i+1}-z_{i}\right|=h \text { for some small } h .
$$

In this approximation, we approximate $g(z)$ with $g\left(z_{i}\right)$ on each arc of length $h$ for which $\left|z-z_{i}\right| \leqslant h / 2$. 
The inaccuracy of this approximation is

$$
\left|g(z)-g\left(z_{i}\right)\right| \leqslant\left(\max _{z}\left|g^{\prime}(z)\right| \cdot\left|z-z_{i}\right|\right) \leqslant \max _{z}\left|g^{\prime}(z)\right| \cdot(h / 2)
$$

Here, $g(z)=\frac{f(z)}{\left(z-z_{0}\right)^{n+1}} \approx \frac{f(z)}{r^{n+1}}$. Thus, $\max _{z}\left|g^{\prime}(z)\right| \leqslant \frac{\max \left|f^{\prime}(z)\right|}{r^{n+1}}=\frac{D}{r^{n+1}}$.

So, the approximation accuracy is $\frac{D}{r^{n+1}} \cdot(h / 2)$. To get accuracy $\varepsilon^{\prime}$, we need to take $h$ for which

$$
\frac{D}{r^{n+1}} \cdot(h / 2)=\varepsilon^{\prime} \text {, i.e., } h=2 \frac{\varepsilon^{\prime}}{D} \cdot r^{n+1} \text {. }
$$

The whole loop $\gamma$ of length $2 \pi \cdot r$ should be covered by intervals of length $h$. These intervals correspond to values $z_{i}$ at which we compute $f(z)$. Thus, we need to compute $f(z)$ for $N=\frac{2 \pi \cdot r}{h}$ points.

Substituting the above expression for $h$, we conclude that we need to compute $f(z)$ at

$$
N=\frac{2 \pi \cdot r \cdot D}{2 \varepsilon^{\prime} \cdot r^{n+1}} \sim r^{-n} \text { points. }
$$

Since $r<1$, this number indeed grows exponentially with $n$. This is exactly what we wanted to show.

\section{Possible Applications}

This result will probably be of interest to theoreticians (like Khalfin) - who are interested in providing physical theories with physically meaningful mathematical foundations.

This result may also have practical applications if we take into account that many times when we encountered a physical process whose properties are difficult to compute, it became possible to use this process to speed up computations. Successes of quantum computing are the latest example of this phenomenon; see, e.g., [7].

From this viewpoint, maybe measurement of the corresponding Taylor coefficients can lead to yet another efficient quantum computing scheme?

\section{Acknowledgments}

This work was supported in part by the National Science Foundation via grants 1623190 (A Model of Change for Preparing a New Generation for Professional Practice in Computer Science) and HRD-1242122 (Cyber-ShARE Center of Excellence).

\section{REFERENCES}

1. Bishop E. Foundations of Constructive Analysis. Wiley, New York, 1967. 
2. Bishop E. and Bridges D.S. Constructive Analysis. Springer, New York, 1985.

3. Bogoliubov N.N., Logunov A.A., Oksak A.I., and Todorov I.T. General Principles of Quantum Field Theory. Kluwer, Dordrecht, 1990.

4. Feynman R., Leighton R., and Sands M. The Feynman Lectures on Physics. Addison Wesley, Boston, Massachusetts, 2005.

5. Kreinovich V., Lakeyev A., Rohn J., and Kahl P. Computational Complexity and Feasibility of Data Processing and Interval Computations. Kluwer, Dordrecht, 1998.

6. Lifschitz V.A. Investigation of constructive functions by the method of fillings. Journal of Soviet Mathematics, 1973, vol. 1, pp. 41-47.

7. Nielsen M. and Chuang I. Quantum Computation and Quantum Information. Cambridge University Press, Cambridge, 2000.

8. Orevkov V.P. New proof of the uniqueness theorem for the differentiable complexvariable functions. Zapiski Nauchnykh Seminarov LOMI, 1974, vol. 40, pp. 119-126 (in Russian).

9. Papadimitriou C.H. Computational Complexity. Addison Wesley, 1994.

10. Thorne K.S. and Blandford R.D. Modern Classical Physics: Optics, Fluids, Plasmas, Elasticity, Relativity, and Statistical Physics. Princeton University Press, Princeton, New Jersey, 2017.

11. Weihrauch K. Computable Analysis. Springer-Verlag, Berlin, 2000.

\title{
МОЖЕМ ЛИ МЫ СОХРАНИТЬ ФИЗИЧЕСКИ ЗНАЧИМУЮ «МАКРО» АНАЛИТИЧНОСТЬ, НЕ ТРЕБУЯ ФИЗИЧЕСКИ БЕССМЫСЛЕННОЙ «МИКРО» АНАЛИТИЧНОСТИ?
}

\author{
О. Кошелева \\ к.ф.-м.н., доцент, е-mail: olgak@utep.edu \\ В. Крейнович \\ к.ф.-м.н., професcop, e-mail: vladik@utep.edu \\ Техасский университет в Эль Пасо, США
}

\begin{abstract}
Аннотация. Физики, работающие над квантовой теорией поля, активно использовали «макро» аналитичность (например, что интеграл аналитической функции по большому замкнутому контуру равен 0), но они согласны с тем, что «микро» аналитичность (возможность разложения в ряд Тейлора) физически не имеет смысла на микроуровне. Многие физики предпочитают физические теории с физически значимыми математическими основами. Итак, возникает естественный вопрос: можем ли мы сохранить физически значимую «макро» аналитичность, не требуя физически бессмысленной «микро» аналитичности? В 1970-х годах была сделана попытка сделать это с помощью конструктивной математики, в которой разрешены только объекты, сгенерированные алгоритмами. Это не сработало, но, как мы показываем в этой статье, желаемое разделение между «макро» и «микро» аналитичностью может быть достигнуто, если мы ограничимся выполнимыми алгоритмами.
\end{abstract}

Ключевые слова: математические основы физики, аналитическая функция, конструктивная математика, выполнимые алгоритмы.

Дата поступления в редакциию: 09.02.2020 